\title{
Ultrasound Imaging of the Spine for Central Neuraxial Blockade: a Technical Description and Evidence Update
}

\author{
Hari Kalagara $^{1}$ (D) $\cdot$ Harsha Nair $^{2} \cdot$ Sree Kolli $^{2} \cdot$ Gopal Thota $^{3} \cdot$ Vishal Uppal $^{4}$ (D) \\ Accepted: 7 June 2021 / Published online: 26 June 2021 \\ (C) This is a U.S. government work and not under copyright protection in the U.S.; foreign copyright protection may apply 2021
}

\begin{abstract}
Purpose of Review This article describes the anatomy of the spine, relevant ultrasonographic views, and the techniques used to perform the neuraxial blocks using ultrasound imaging. Finally, we review the available evidence for the use of ultrasound imaging to perform neuraxial blocks.

Recent Findings Central neuraxial blockade using traditional landmark palpation is a reliable technique to provide surgical anesthesia and postoperative analgesia. However, factors like obesity, spinal deformity, and previous spine surgery can make the procedure challenging. The use of ultrasound imaging has been shown to assist in these scenarios.

Summary Preprocedural imaging minimizes the technical difficulty of spinal and epidural placement with fewer needle passes and skin punctures. It helps to accurately identify the midline, vertebral level, interlaminar space, and can predict the depth to the epidural and intrathecal spaces. By providing information about the best angle and direction of approach, in addition to the depth, ultrasound imaging allows planning an ideal trajectory for a successful block. These benefits are most noticeable when expert operators carry out the ultrasound examination and for patients with predicted difficult spinal anatomy. Recent evidence suggests that pre-procedural neuraxial ultrasound imaging may reduce complications such as vascular puncture, headache, and backache. Neuraxial ultrasound imaging should be in the skill set of every anesthesiologist who routinely performs lumbar or thoracic neuraxial blockade. We recommend using preprocedural neuraxial imaging routinely to acquire and maintain the imaging skills to enable success for challenging neuraxial procedures.
\end{abstract}

Keywords Ultrasonography · Central neuraxial block · Spine · Anesthesia $\cdot$ Analgesia $\cdot$ Diagnostic imaging $\cdot$ Ultrasound Epidural $\cdot$ Spinal

\section{Introduction}

Central neuraxial blockade (CNB) comprises of epidural or spinal anesthesia or analgesia, is an established technique for

This article is part of the Topical Collection on Regional Anesthesia

Hari Kalagara

hkalagara@uabmc.edu

1 Department of Anesthesiology, The University of Alabama at Birmingham (UAB), Birmingham, AL, USA

2 Department of General Anesthesia and Acute Pain Management, Cleveland Clinic, Cleveland, OH, USA

3 Department of Anaesthesiology, Care Hospitals, Hyderabad, India

4 Department of Anesthesia, Perioperative Medicine and Pain Management, Dalhousie University, Nova Scotia Health Authority and Izaak Walton Killam Health Centre, Halifax, Nova Scotia, Canada surgical anesthesia and postoperative analgesia. The landmark-based technique of the palpation of spinous process with the loss of resistance to saline or air has a high success rate for epidural placement in patients with normal anatomy [1]. Similarly, spinal anesthesia can be performed using landmark technique with needle tactile response and flow of cerebrospinal fluid acting as a clear endpoint. However, factors like obesity, congenital/acquired or age-related altered anatomy, and previous spine surgery can make these procedures technically challenging.

The ultrasound imaging can assist in two unique ways for the placement of central neuraxial block [2]. First, ultrasound scanning prior to skin puncture has been proven to help identify midline and the appropriate interspace, any abnormal anatomy, depth to the epidural space, and planned needle trajectory $[3,4 \bullet]$. Second, real-time ultrasound-guidance has been described [5]. However, it is currently a cumbersome technique with limited clinical utility and will only be discussed briefly in the article. 
This review describes the relevant anatomy, ultrasonographic imaging views, and re-examines the current literature to better understand the role of ultrasound in the placement of neuraxial blockade.

\section{Gross Anatomy and Sonoanatomy of the Lumbar Vertebrae}

In-depth knowledge of gross and sonoanatomy of the vertebrae and the vertebral canal is paramount, for understanding neuraxial imaging. Figure 1 shows a typical lumbar vertebra. Each vertebra is made up of a body and arch. The arch is composed of pedicles, a spinous process (SP), lamina, superior and inferior articular processes (APs), and transverse processes (TPs). The vertebral canal is formed by the spinous process and lamina posteriorly, pedicles laterally, and vertebral bodies anteriorly. Within the vertebral canal lie the thecal sac and its contents. The epidural space lies outside the thecal sac within the vertebral canal. The identification of these key anatomical structures in para-sagittal and transverse views enables better performance of ultrasound-guided neuraxial interventions.

The bony structures of the lumbar vertebrae appear as hyperechoic white lines on ultrasound imaging with black acoustic shadowing underneath. Figure 2 shows the bony windows through which the ultrasound beam can pass through and encounter the thecal sac. These are called the interlaminar and interspinous spaces. The interlaminar space is located posterolateral and the interspinous space in the midline posteriorly to the thecal sac. The intervertebral foramina are located laterally from where the spinal nerve roots emerge (Fig. 3).

The ligamentum flavum, epidural space, and posterior dura often appear as single or sometimes double hyperechoic white structure referred to as the posterior complex (PC). The anterior dura, posterior longitudinal ligament, and the posterior

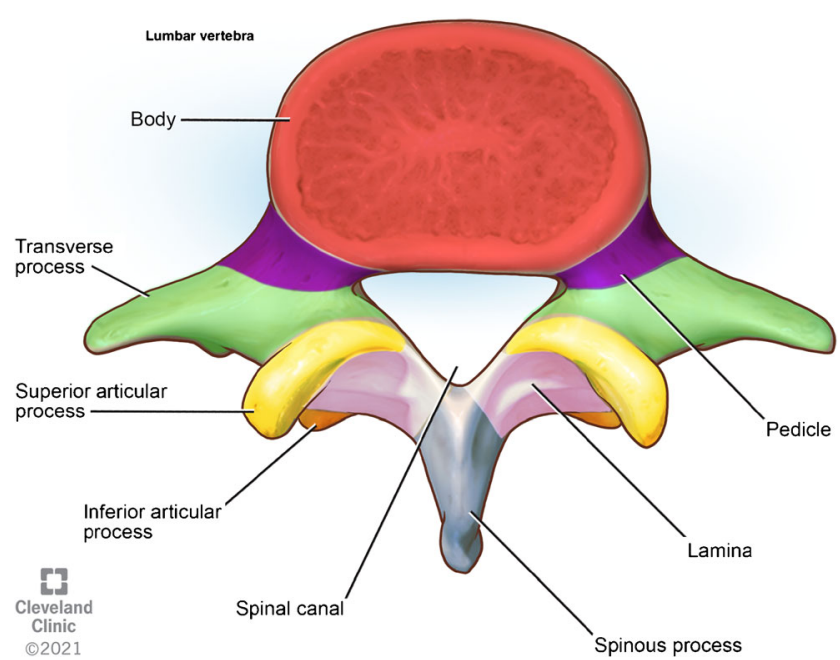

Fig. 1 Lumbar vertebra. (This image is produced with permission from Cleveland Clinic Center for Medical Art \& Photography)

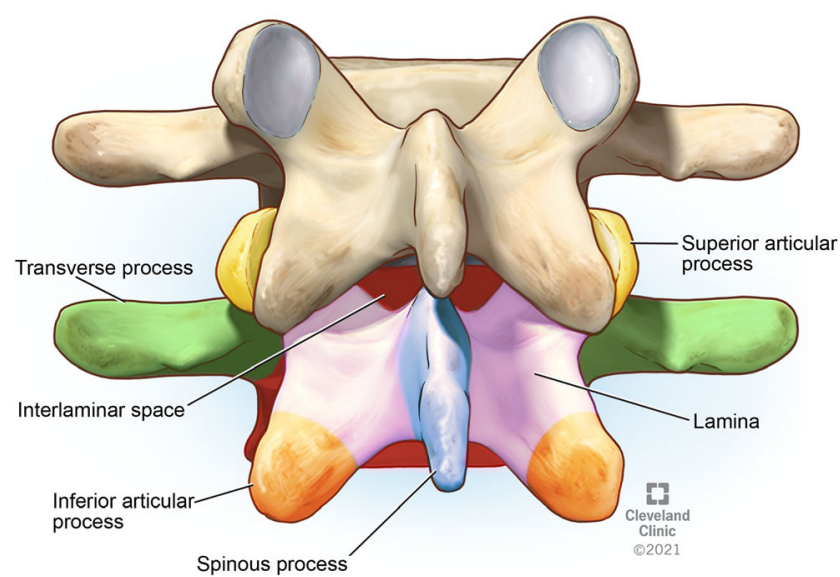

Fig. 2 Posterior view of adjacent lumbar vertebrae. (This image is produced with permission from Cleveland Clinic Center for Medical Art \& Photography)

aspect of the vertebral body are visible as a single hyperechoic white line referred to as the anterior complex (AC). The anterior and posterior complexes can be visualized in both interlaminar and interspinous views with the thecal sac in between.

\section{Sonographic Views of the Lumbar Vertebrae}

Most commonly, a curvilinear low-frequency (2-5 MHz) ultrasound transducer is utilized for neuraxial scanning with the patient in the sitting or lateral decubitus position. This transducer allows deeper penetration and wider viewing of deeper structures through the bony windows. The authors recommend pre-procedural scanning routinely for all patients prior to spinal anesthesia. This may allow the clinicians to get comfortable with spine imaging in patients with normal anatomy and may improve success in more challenging scenarios.

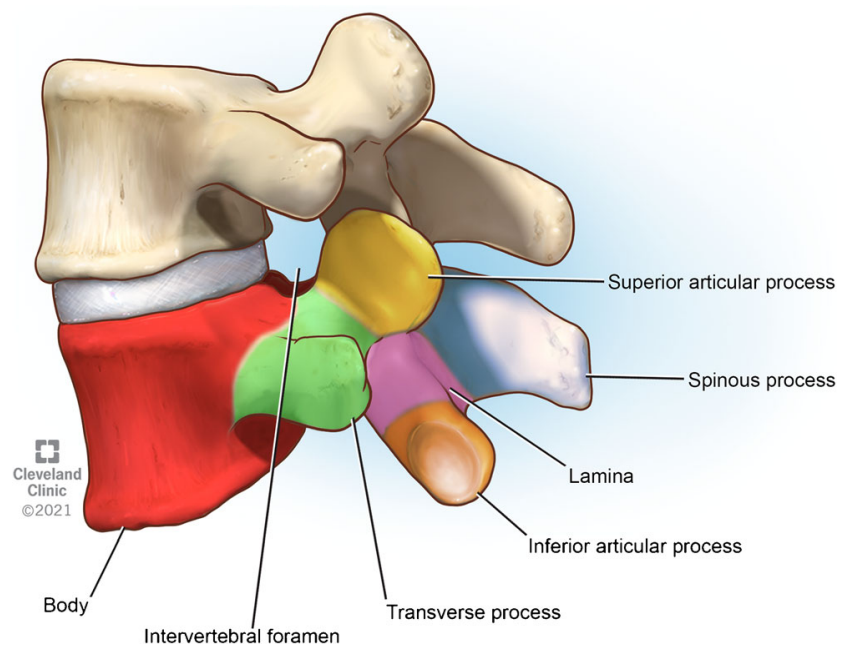

Fig. 3 Lateral view of adjacent lumbar vertebrae. (This image is produced with permission from Cleveland Clinic Center for Medical Art \& Photography) 
Figures 4 and 5 show the transducer orientations during the sagittal and transverse systematic scanning that is performed for the correct location of intervertebral level, location of the midline, measurement of the depth to the epidural space, and identification of other relevant structures. Conventionally, three para-sagittal and two transverse views are performed for complete neuraxial scanning.

\section{Para-Sagittal Transverse Process View}

The ultrasound transducer is placed in a para-sagittal plane a few centimeters lateral of midline as shown in

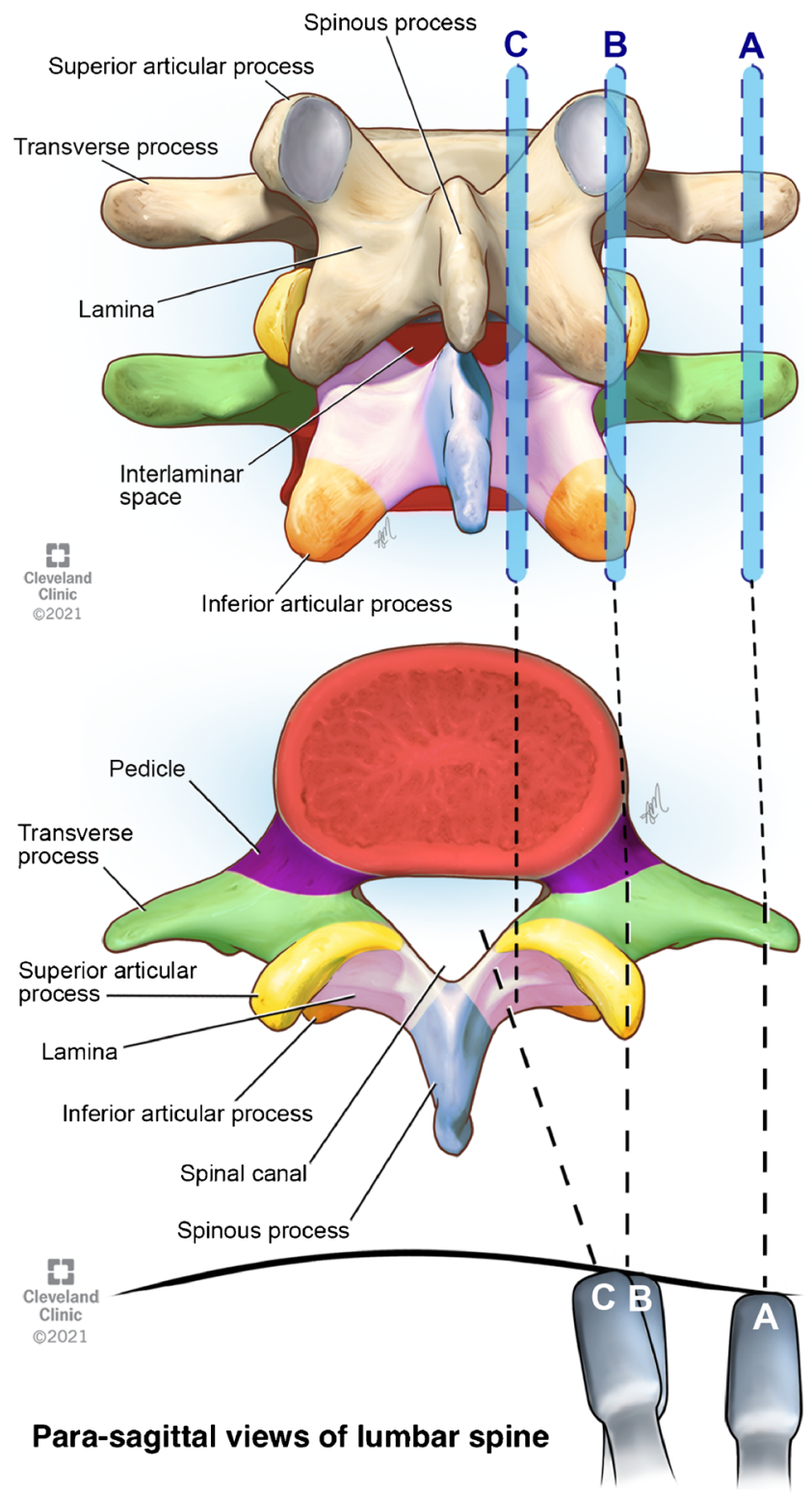

Fig. 4 Para-sagittal views of the lumbar spine. (This image is produced with permission from Cleveland Clinic Center for Medical Art \& Photography)
Fig. 4, probe position A and Fig. 6. The surface of the transverse processes are seen as round hyperechoic outlines with deeper hypoechoic shadows as dark finger-like projections, as shown in Fig. 7. This is described as a "trident sign." The psoas major muscle is seen between these hypoechoic shadows.

The para-sagittal scanning can be used for ascertaining the exact vertebral level before the procedure. In this method, the ultrasound transducer is placed over the sacrum to identify the L5 transverse process and L5-S1 intervertebral space (Figs. 8 and 9). The transducer is then slid cranially to identify the respective L5-L4, L4-L3, and L3-L2 interspaces.

\section{Para-Sagittal Articular Process View}

The probe is then moved medially until a continuous white hyperechoic line with "camel humps" is seen, indicating the facet joint's articular processes (Fig. 4 probe position B). It is difficult to see any neuraxial structures in this view as the bone is continuous and does not permit ultrasound signals beyond the articular processes (Fig. 10).

\section{Para-Sagittal Interlaminar (Oblique) View}

From the para-sagittal articular process view, the probe is tilted medially toward the median sagittal plane to bring the lamina into view (Fig. 4 probe position C). This view can also be referred to as a para-sagittal oblique view. The sloping lamina appears as white hyperechoic lines described as a "sawtooth" or "horsehead" pattern (Fig. 11). The gaps represent the interlaminar spaces through which the posterior and anterior complexes are visualized. This is the most important window in sagittal scanning to identify interspaces. The appropriate interlaminar space is identified and marked on the skin using this view. This view is also helpful in identifying the open spaces for a paramedian approach to neuraxial anesthesia. If no open windows are noticed in the midline, but adequate windows are observed in the para-sagittal interlaminar scan, the clinician could directly start with a para-median approach.

\section{Transverse Spinous Process View}

After identification of the appropriate interspace using the para-sagittal interlaminar view, the probe is turned $90^{\circ}$ to obtain a transverse spinous process view (Fig. 12). The tip of the spinous process is identified as a white hyperechoic line with acoustic shadowing beneath it with a sloping lamina seen laterally (Fig. 13). This is the key view for the identification of midline (Fig. 5 probe position A) and the interspinous spaces between the consecutive spinous processes in obese 
Fig. 5 Transverse views of the lumbar spine. (This image is produced with permission from Cleveland Clinic Center for Medical Art \& Photography)

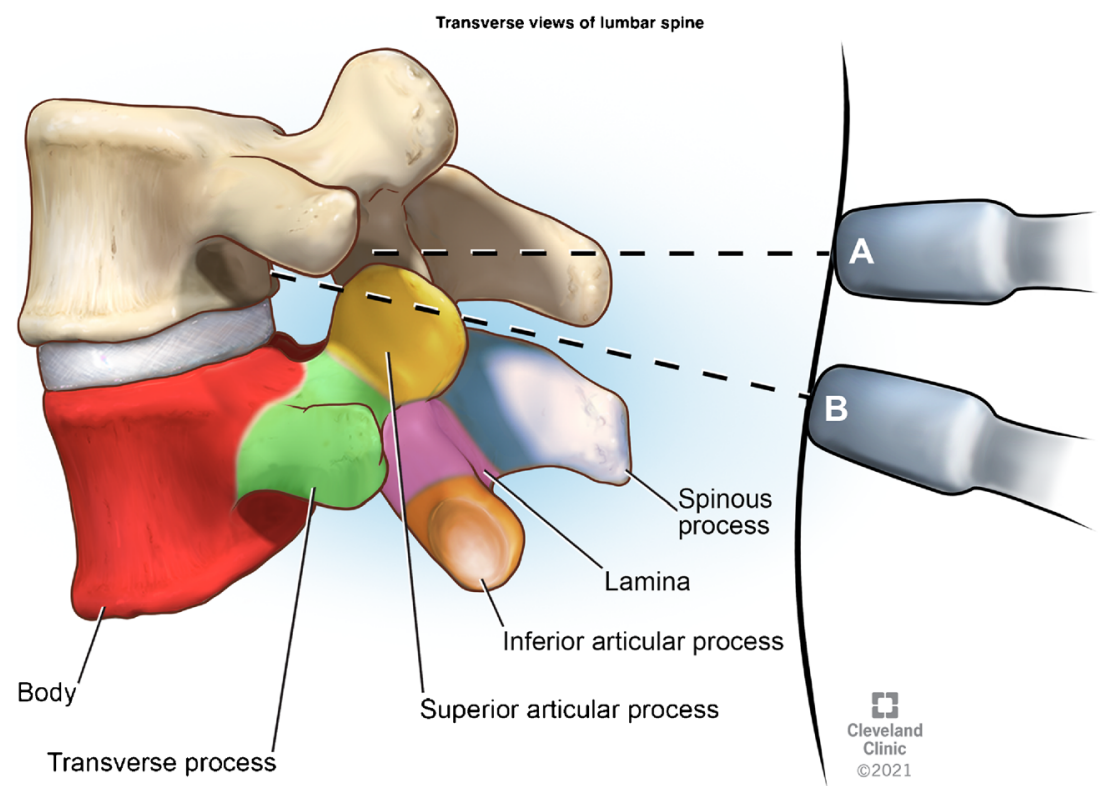

patients. We recommend using M-mode line for determining the exact midline in this view (Fig. 14).

\section{Transverse Interspinous View}

After identification of the spinous process, the probe is either moved cephalad or caudad to the interspinous space (Fig. 5 probe position B). This view, also known as the transverse interlaminar view, allows for visualization of the posterior and anterior complexes along with articular and transverse processes laterally (Fig. 15). The depth of the posterior complex from the skin can be noted in this view and is useful for

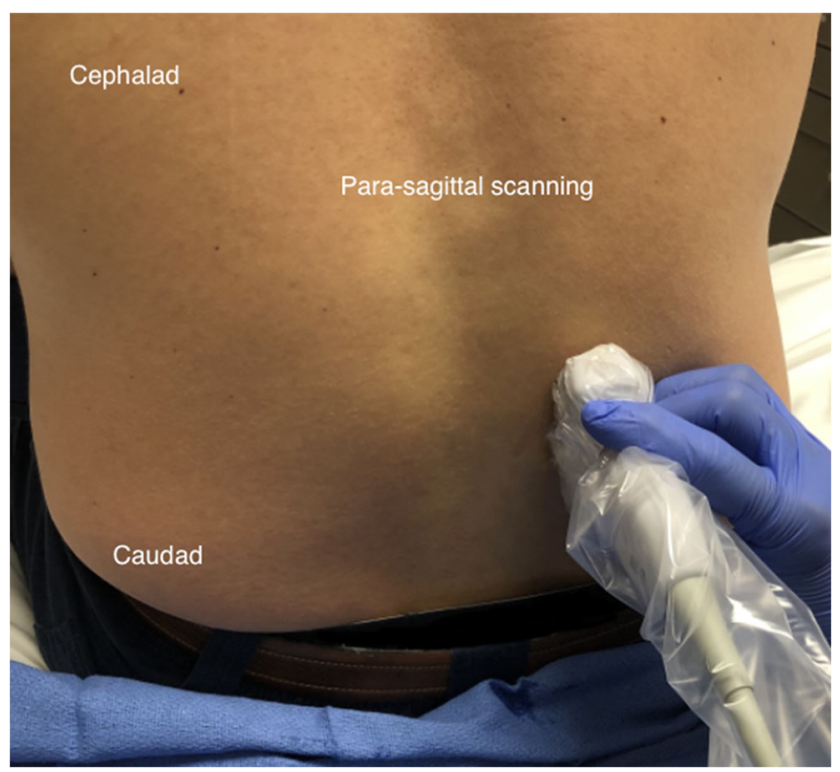

Fig. 6 Probe position for para-sagittal transverse process view scanning guiding epidural placement. The angle of the probe required to visualize posterior and anterior complexes in this view facilitates the angle of incidence for needle entry for successful neuraxial placements. After identification of posterior and anterior complexes, the ink markings are made in horizontal and vertical directions are joined together to mark the entry point for neuraxial procedures (Figs. 17 and 18). The intrathecal space is seen as hypoechoic space between the posterior and anterior complexes. An un-obstructed interlaminar space is a space where both the posterior and anterior complexes can be clearly visualized. The widest, unobstructed interspace can be used for access to the neuraxis. This is done by sliding the ultrasound transducer caudad and cephalad in the transverse interspinous process view. Maintaining the visibility of the anterior complex for a larger distance indicates a wider interspinous space.

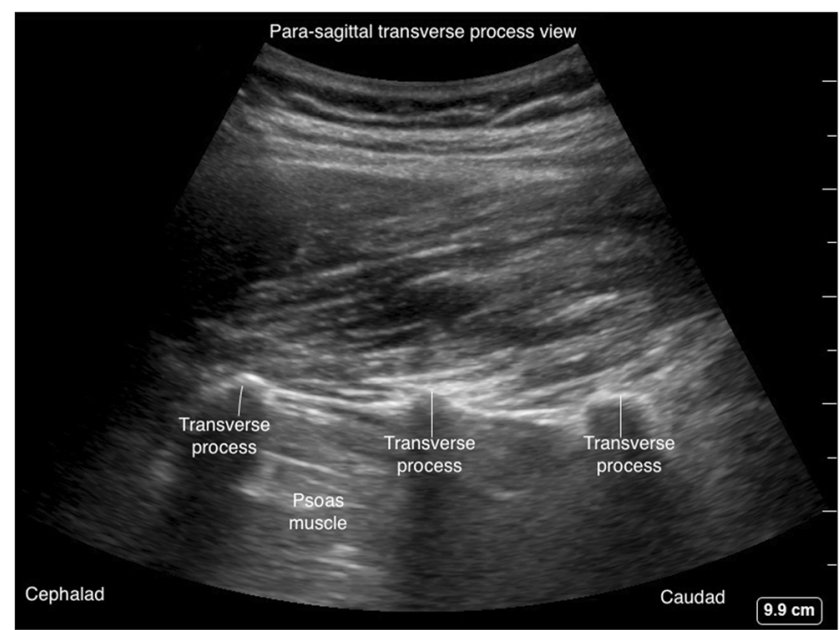

Fig. 7 Para-sagittal transverse process view (trident sign) 


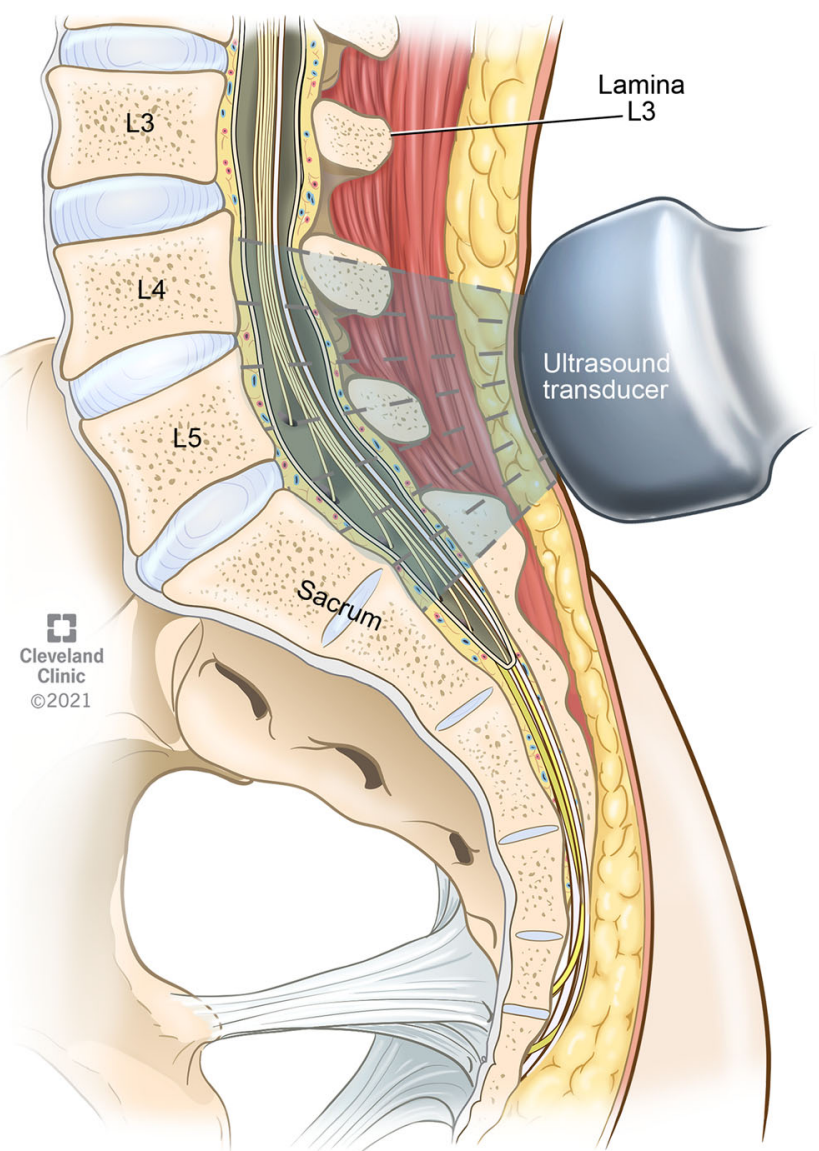

Fig 8 Para-sagittal view of sacrum-lower lumbar vertebrae. (This image is produced with permission from Cleveland Clinic Center for Medical Art \& Photography)

\section{A Systematic Approach to Pre-Procedural Ultrasound Scanning of the Lumbar Spine}

Although multiple variations of the scanning technique have been described in the literature $[2,4]$, core principles

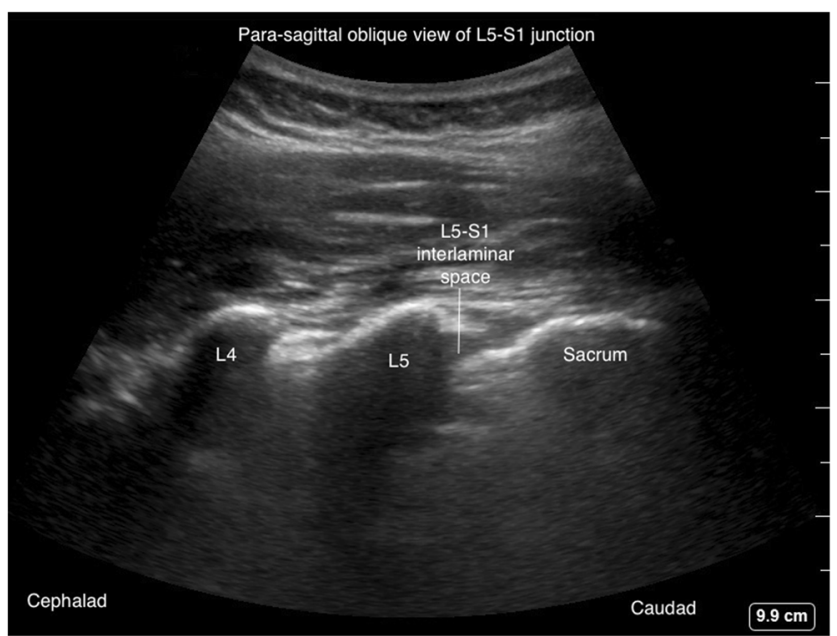

Fig 9 Para-sagittal oblique view of L5-S1 interlaminar space

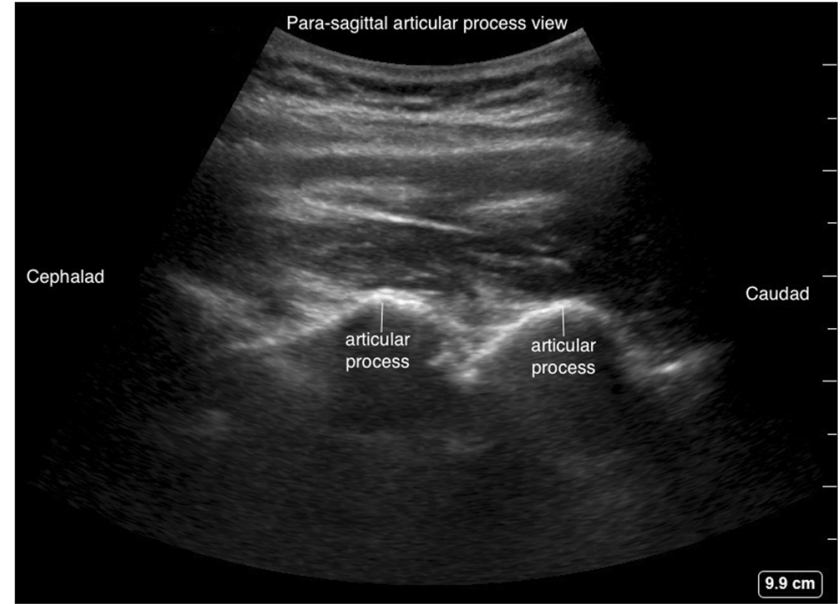

Fig. 10 Para-sagittal articular process view (camel hump sign)

are the same. The following stepwise approach is utilized by the authors.

1. A sitting position is preferable for the procedure. Alternatively, a lateral decubitus position is acceptable.

2. A curvilinear low-frequency transducer $(2-5 \mathrm{MHz})$ is selected, and ultrasound gel is used as a coupling medium.

3. The screen depth is set to $9-11 \mathrm{~cm}$ and adjusted after initial assessment.

4. The scanning is started in the para-sagittal transverse process view. The transverse processes are identified as "trident sign." (Fig. 7)

5. The transducer is slid medially to obtain a parasagittal articular process view identified as "camel humps" (Fig. 10)

6. The transducer is then tilted medially to obtain a parasagittal interlaminar (oblique) view. The laminae appear as a "sawtooth" or "horsehead" and, medially, the posterior complex, anterior complex, and thecal sac are subsequently identified. (Fig.11)

7. The interlaminar spaces (acoustic windows) are counted up from the sacrum (Fig. 9) in the para-sagittal interlaminar view, and the L3-4 level is marked (Fig. 16).

8. The transducer is rotated $90^{\circ}$ to obtain a transverse spinous process view at the desired interspace. The midline (vertical marking) is marked with the aid of the M-mode midline marker as shown in Figs. 13, 14, and 17.

9. The transverse interspinous view is obtained by sliding the probe slightly cephalad or caudad. This enables the identification of the posterior complex, anterior complex, and thecal sac. The interspaces are marked laterally as shown in Figs. 15 and 17 (transverse marking).

10. The intersection of the vertical and transverse skin markings is the needle entry point for ultrasound-assisted neuraxial procedures. (Fig. 18) 


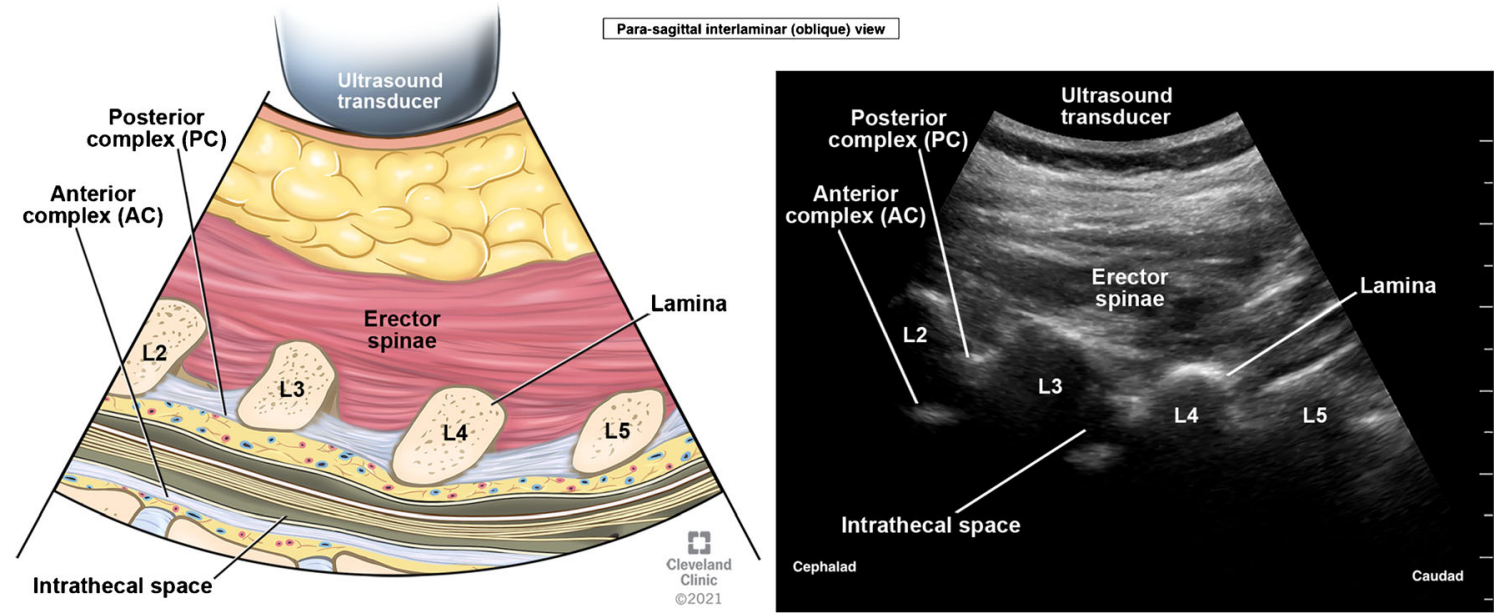

Fig. 11 Para-sagittal interlaminar (oblique) view (horsehead/sawtooth sign). (This image is produced with permission from Cleveland Clinic Center for Medical Art \& Photography)

\section{Fast Track Spine Scanning}

1. Identify inter-laminar level in the para-sagittal interlaminar view and mark. (Fig. 11)

2. Identify midline using in the transverse spinous process view and mark. (Fig. 13)

3. Identify the best window in the transverse interspinous view and mark for needle entry. (Figs. 15 and 18)

\section{The Utility of a Pre-Procedural Scan}

The following information could be obtained by use of a preprocedural ultrasound scan of the spine:
1. Identification of the correct vertebral level.

2. Identification of midline.

3. Assessment of angulation of the needle for successful access to the epidural or intrathecal space.

4. Identification of an open and wide intervertebral space for needle insertion.

5. Identification of best place for needle point entry.

6. Assessment of depth for needle length selection.

7. Assessment of abnormal spine anatomy and adjusting the needle insertion angle, as in scoliosis.

8. Identification of an un-obstructed interlaminar space in the presence of spinal instrumentation.

9. Deciding midline or paramedian approach for needle insertion.
Fig. 12 Probe position for transverse scanning

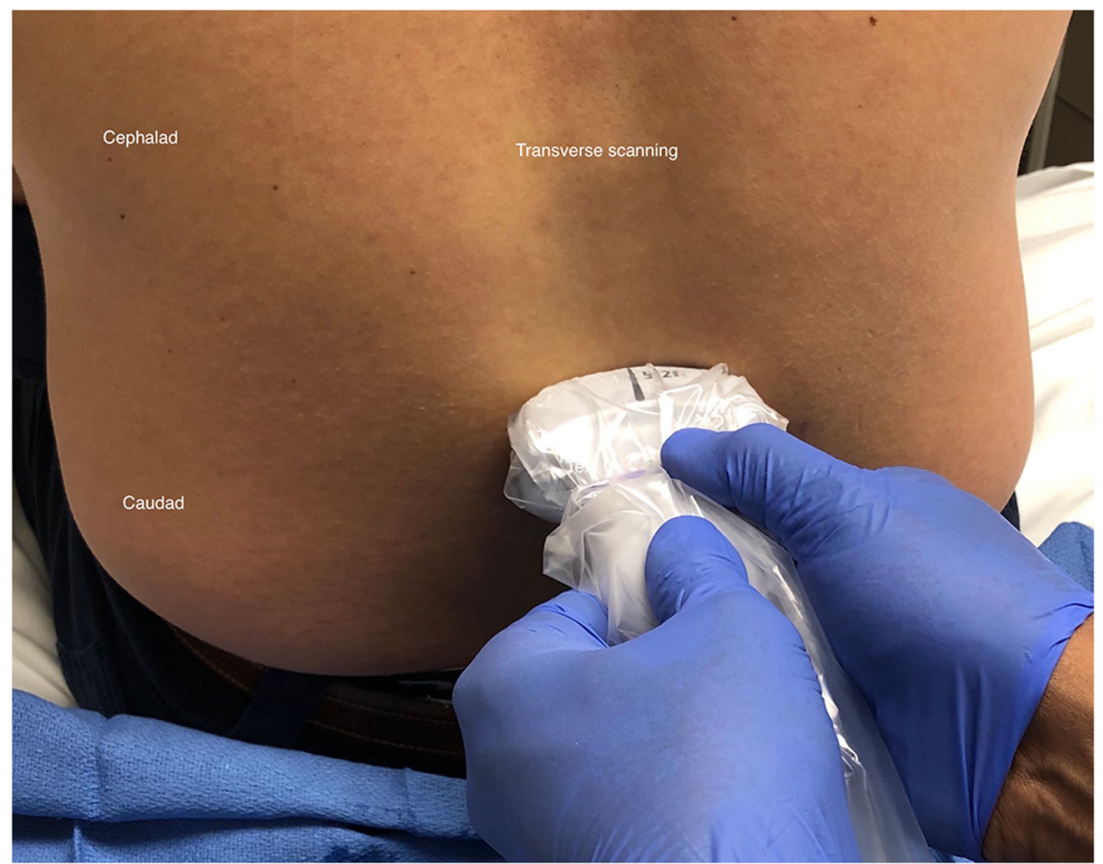




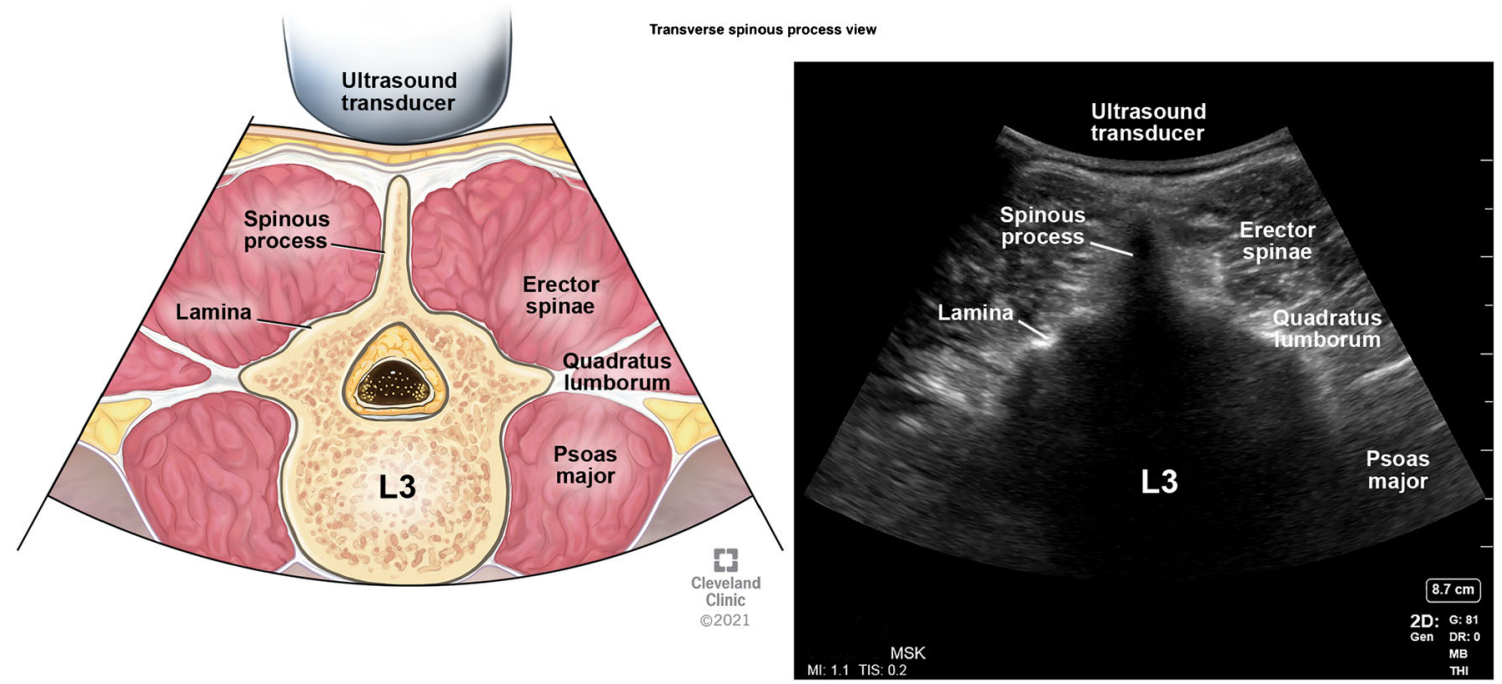

Fig. 13 Transverse spinous process view. (This image is produced with permission from Cleveland Clinic Center for Medical Art \& Photography)

\section{Limitations}

1. Spine imaging has a steep learning curve and requires a sound understanding of anatomy and how the acoustic shadows are produced by different parts of the vertebrae.

2. Lumbosacral transitional vertebrae are a common finding reported in $4-21 \%$ of the general population and can lead to confusion with respect to the numbering of lumbar discs and vertebrae [6].

\section{Thoracic spine}

The upper thoracic (T1-T4) and lower thoracic (T9-12) vertebrae have similar geometry to cervical and lumbar vertebrae and amenable for US scanning (Fig. 19). The mid-thoracic (T5-T8) vertebrae have extreme inferior angulation of spinous process and pose technical challenges for ultrasound scanning (Fig. 20).

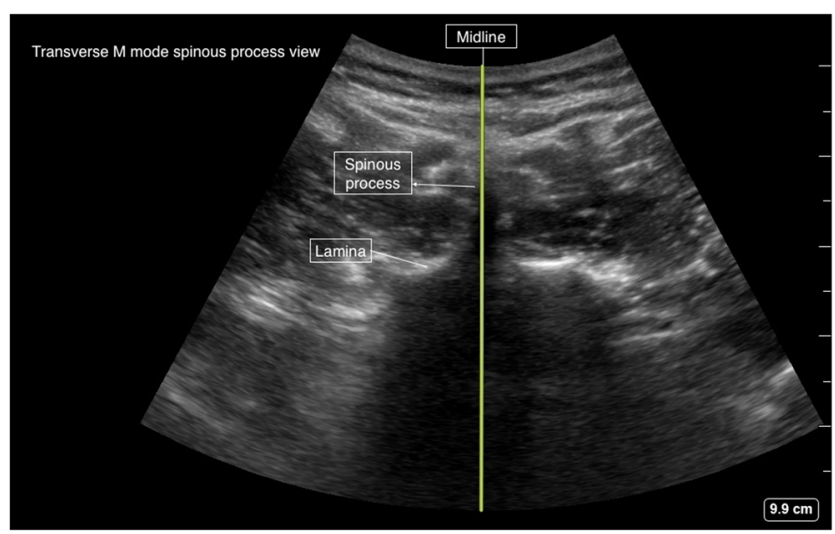

Fig. 14 Transverse M mode spinous process view
The para-sagittal windows can be obtained by beginning laterally with identification of ribs and pleura, then moving medially with identification of transverse process, articular process, and lamina. The para-sagittal interlaminar view (Figs. 21 and 22) is used to locate the interlaminar space as a marking point for the neuraxial procedure. The transverse views (Figs. 23 and 24) are challenging to obtain in the midthoracic spine as the transverse interspinous windows are narrow here. The presence of a rib marks the junction of the T12 and $\mathrm{L} 1$ vertebra. The $12^{\text {th }}$ rib can be identified to locate the T12 vertebra, and the counting-down approach can be used to locate accurate lumbar intervertebral levels, or the countingup approach can be used to locate the correct thoracic intervertebral level. Alternatively, the correct level can be determined by counting down from the T1 level, after locating the first rib.

\section{Current Evidence for the Use of Ultrasound Imaging of the Spine to Facilitate CNB}

There are numerous systematic and narrative reviews that have synthesized the evidence on the role of ultrasound in the placement of neuraxial blocks in various patient populations. The important findings from each of these reviews are listed chronologically in Table 1.

The 2013 meta-analysis by Shaik et al. evaluated ultrasound imaging for lumbar punctures and epidural catheterizations [19]. They included 14 randomized controlled trials (RCTs) with 1334 subjects and found that ultrasound imaging reduced the risk of failed procedures (risk ratio $0.21,95 \%$ confidence interval 0.10 to $0.43, p<0.001)$. The number needed to treat (NNT) to prevent one failed procedure was sixteen. After subgroup analysis, they found lower risk of both failed lumbar puncture (RR $0.19 ; 0.07$ to $0.56 ; p=0.002$ ) and epidural catheterization (RR $0.23 ; 0.11$ to $0.65 ; p=0.005$ ) 


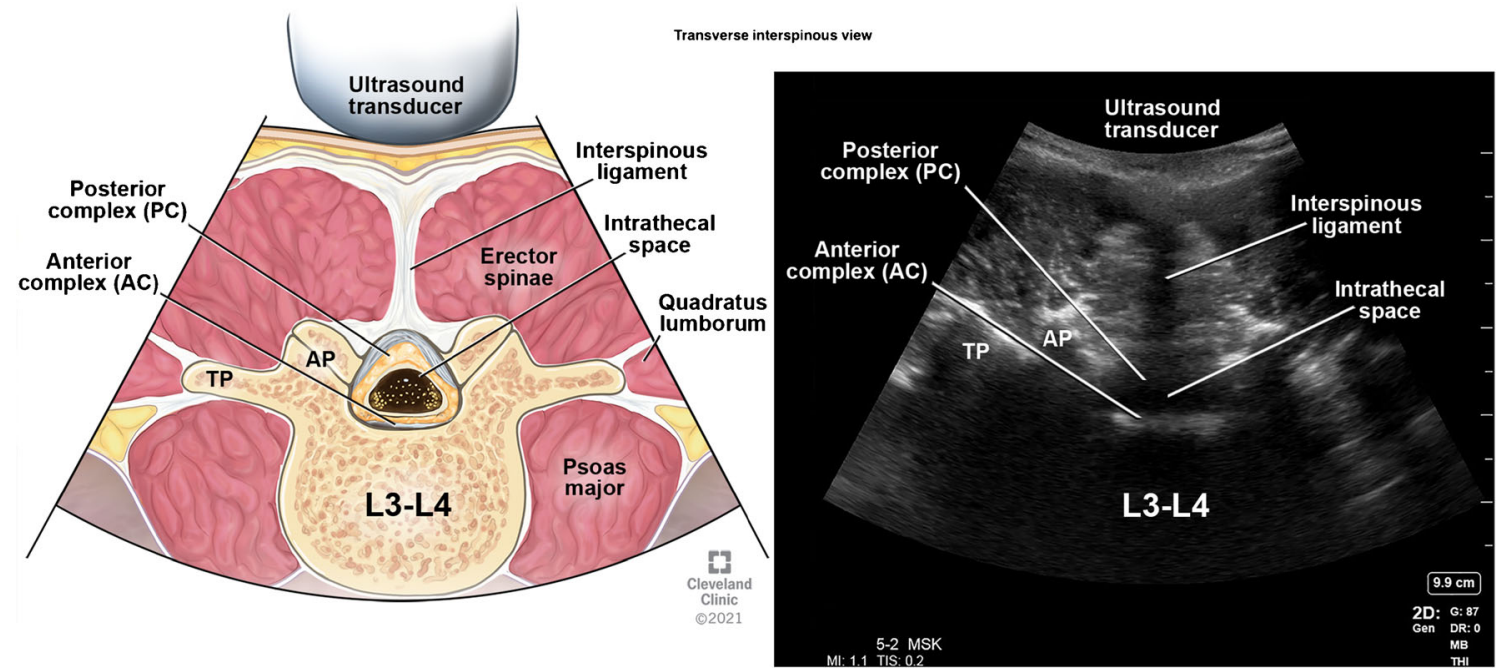

Fig. 15 Transverse interspinous view. (This image is produced with permission from Cleveland Clinic Center for Medical Art \& Photography)

with the use of ultrasound imaging. With regards to safety, the authors also found that ultrasound imaging significantly reduced the risk of traumatic procedures [risk ratio of 0.27 ( 0.11 to 0.67$) p=0.005]$, total number of insertion attempts [mean difference $-0.44(0.64$ to $0.24, p<0.001)$ ], and number of redirections [mean difference $-1.00(-1.24$ to $-0.75, p$ $<0.001)]$.

Perlas et al. performed a systematic review and metaanalysis looking at RCTs and cohort studies to assess lumbar neuraxial ultrasound for spinal and epidural anesthesia in 2016 [18••]. They included 31 RCTs and one meta-analysis. The authors found reasonable evidence for the accuracy of ultrasound imaging to identify lumbar intervertebral spaces compared to landmark palpation alone. An excellent correlation was found between ultrasound-measured depth and

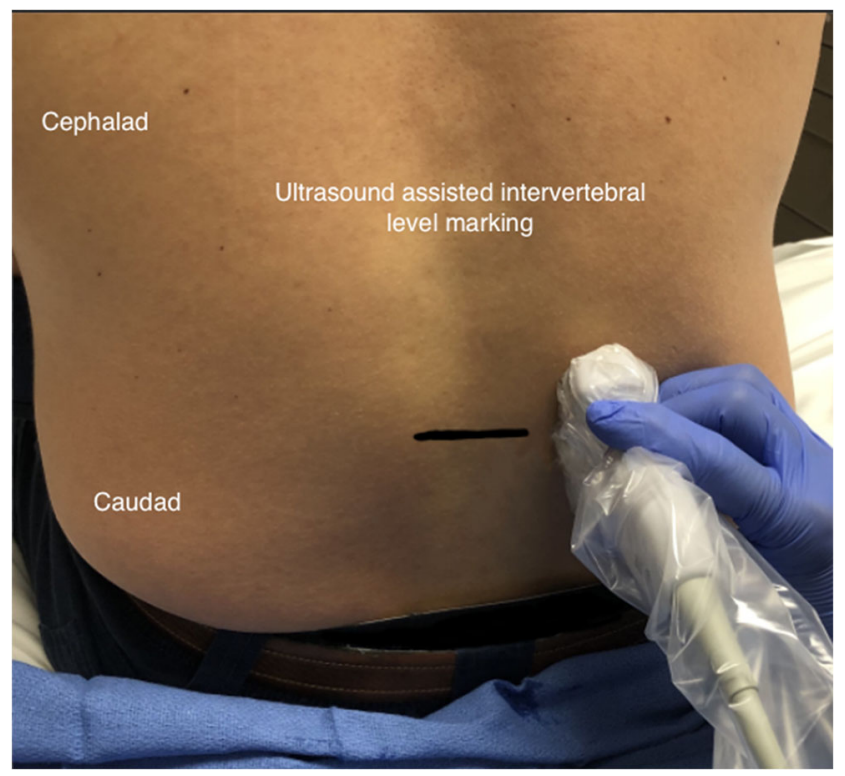

Fig. 16 Marking of intervertebral level (interlaminar space) needle insertion depth to the epidural or intrathecal space. The ultrasound guidance resulted in a reduced failure rate with a risk reduction of $79 \%$ (RR 0.21) for failed lumbar puncture or epidural catheterization. The ultrasound use reduced the risk of traumatic procedures and total needle redirections required for success (MD $-1.00 ; p<0.001$ ).

In 2017, Elgueta et al. performed a narrative review with a slightly wider scope assessing the evidence for the role of ultrasound in the neuraxial blockade that included the pediatric and chronic pain patient populations [16]. They found that when compared to conventional palpation of landmarks, ultrasound preprocedural scanning results in fewer needle passes/insertions and skin punctures for neuraxial blocks in

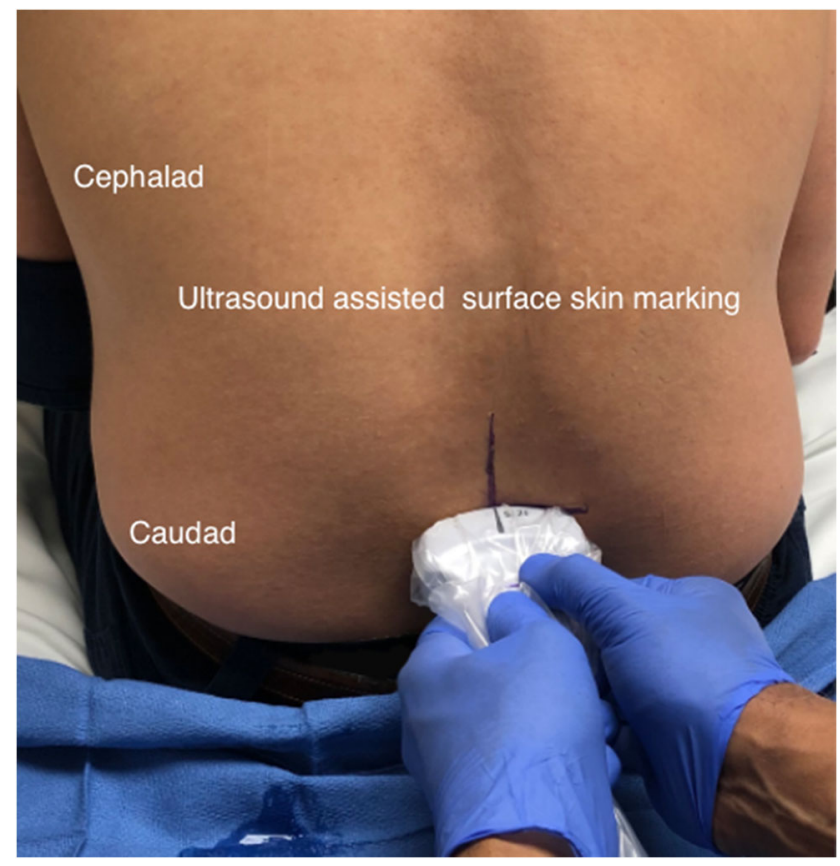

Fig. 17 Ultrasound assisted surface skin markings 


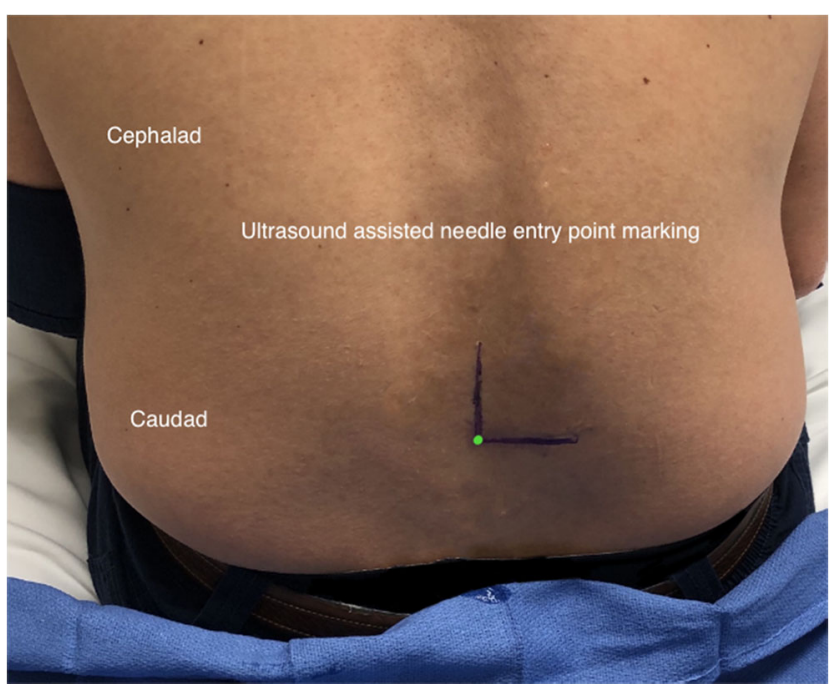

Fig. 18 Ultrasound assisted needle entry point marking

obstetrical and surgical patients, but these benefits were most evident when experienced operators performed the ultrasound scans and for patients likely to have difficult spinal anatomy.

A more recent RCT performed by Li et al. in 2019 examined the role of ultrasound imaging for spinal anesthesia in 80 potentially difficult obstetric patients (BMI $>30 \mathrm{~kg} / \mathrm{m} 2$ in the lateral position) compared to traditional landmark technique [21]. A single experienced investigator performed all ultrasound examinations and skin markings. They found a significantly higher first-attempt success rate for the ultrasound group (87.5\%) vs. the control group $(52.5 \%)(p=0.001)$. Additionally, the ultrasound group had fewer number of skin punctures $(1.2$ vs. $3.6, p<0.001)$ and fewer cases requiring $>$ 10 needle passes ( 1 vs. $17, p<0.001$ ).

In 2020, Park et al. examined the role of pre-puncture ultrasound scanning for placement of spinal anesthesia in patients with abnormal spinal anatomy [22]. In this RCT, all patients were undergoing elective orthopedic surgery under spinal anesthesia with a set of defined lumbar spine abnormalities. These abnormalities included mild to severe lumbar

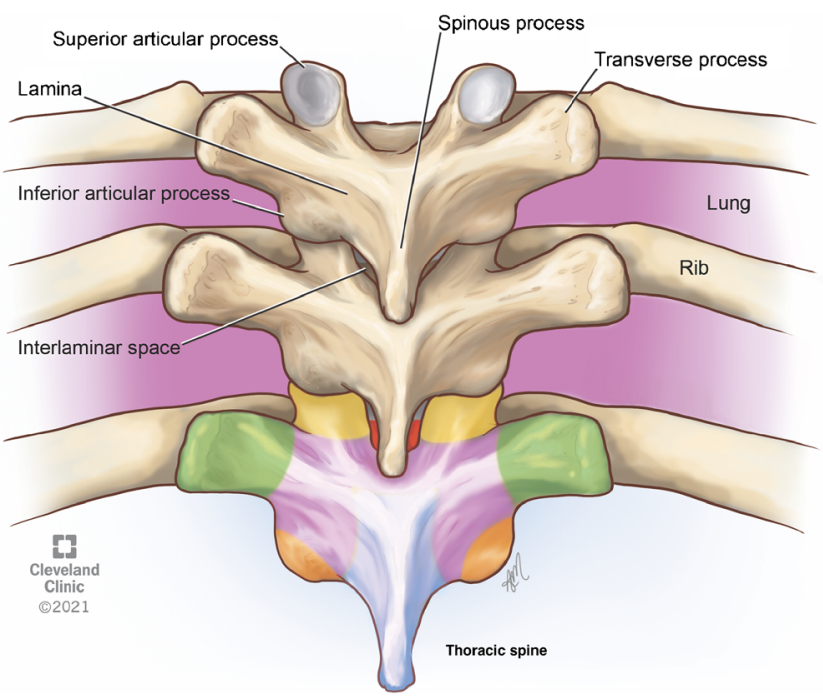

Fig. 20 Thoracic vertebrae. (This image is produced with permission from Cleveland Clinic Center for Medical Art \& Photography)

scoliosis with a Cobb angle $\geq 10^{\circ}$, or a history of lumbar surgery involving L2-L5 vertebra. The control group utilized classic anatomical landmarks for placement. The authors found the ultrasound group had a successful dural puncture with the first attempt (one skin puncture) in $90.9 \%$ vs. $40.9 \%$ in the control group $(p<0.001)$. In terms of needle passes, the ultrasound group had $1^{\text {st }}$ pass success in $50.0 \%$ vs. $9.1 \%$ in the control group $(p<0.001)$. While the actual needling time in the ultrasound group was $38 \mathrm{~s}$ compared to $118 \mathrm{~s}$ in the landmark group, the total procedure time for both groups was roughly the same $146 \mathrm{~s}$ vs. $141 \mathrm{~s}$.

\section{Evidence of Ultrasound-Guidance for Thoracic Epidural}

While many RCTs have examined the use of ultrasound for lumbar neuraxial block placement, there are relatively few studies of ultrasound-guided thoracic epidural placement. Auyong et al. in 2017 evaluated the role of ultrasound pre-
Fig. 19 Para-sagittal and transverse views of thoracic spine. (This image is produced with permission from Cleveland Clinic Center for Medical Art \& Photography)
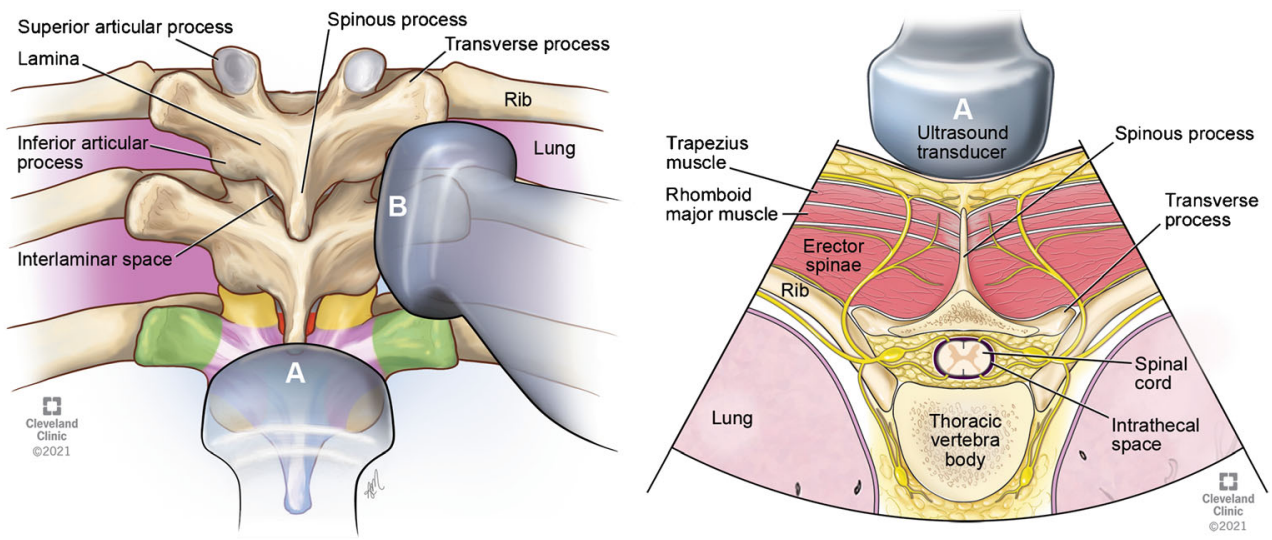


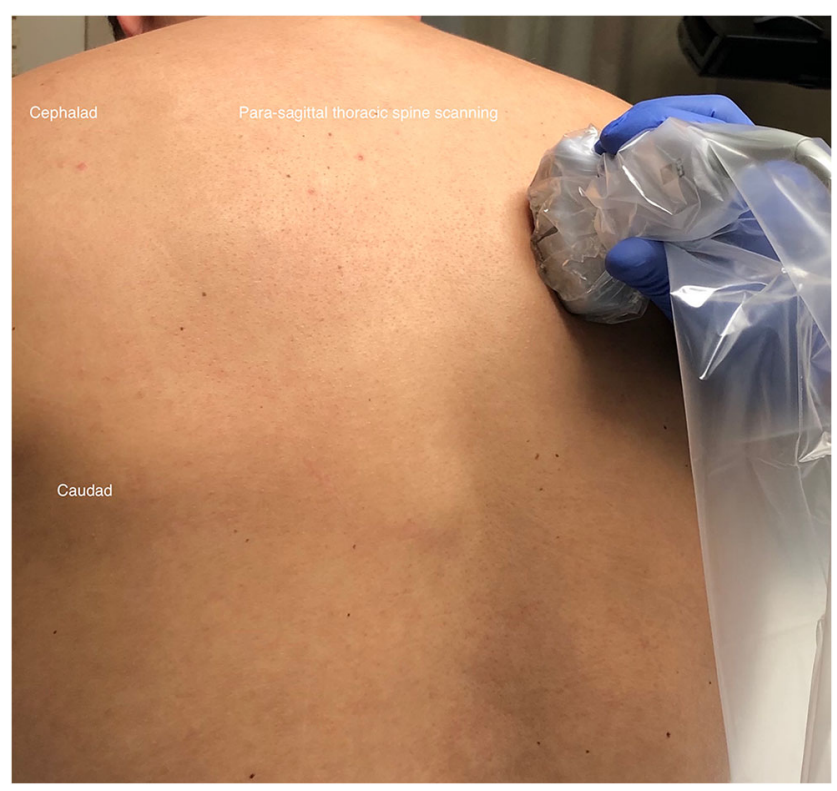

Fig. 21 Probe position for para-sagittal thoracic spine scanning

scanning compared with standard palpation technique for thoracic epidural catheter placement in an RCT of 70 patients [23•]. They did not find a statistically significant difference in procedure-related time. However, ultrasound assistance resulted in fewer needle skin punctures and lower procedural pain scores. Similarly, Hasanin et al. in an RCT of 48 patients [24] reported significantly reduced puncture attempts 1 vs. $1.5(p=0.008)$, and fewer needle redirections in the ultrasound group. However, currently, it remains uncertain if ultrasound-imaging has a clinically relevant impact on thoracic epidural placement.

\section{Real-Time Ultrasound Guidance for Neuraxial Procedures}

One of the main drawbacks of pre-puncture scanning is that the actual procedure is still "blind." Additionally, pre-

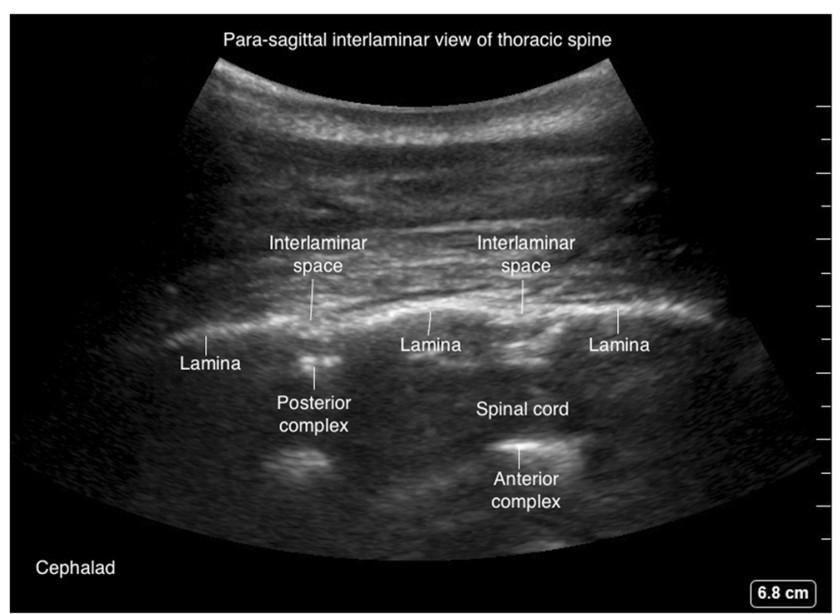

Fig. 22 Para-sagittal interlaminar (oblique) view of thoracic spine

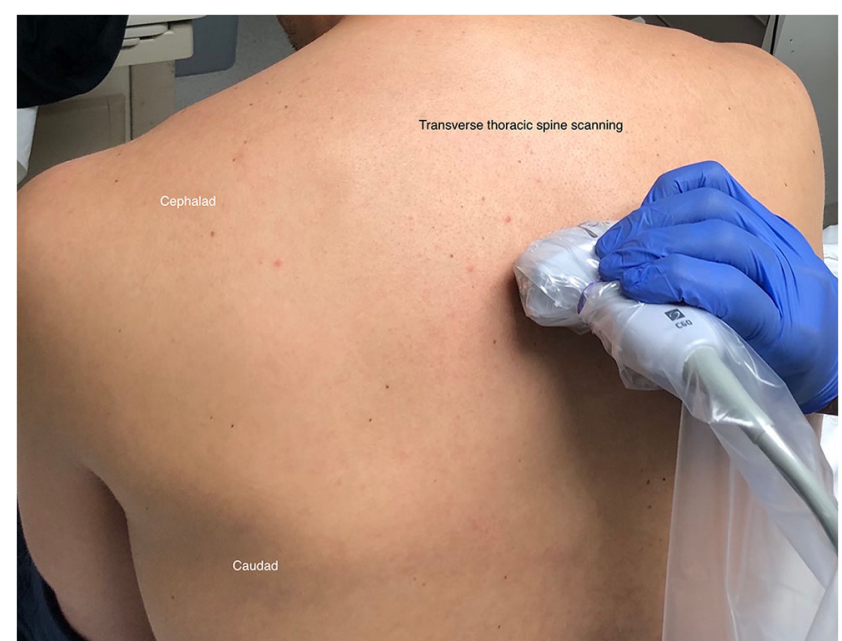

Fig. 23 Probe position for transverse thoracic spine scanning

puncture scanning provides the operator with measurements at a specific time with the patient in a specific position. These measurements become inaccurate with patient movement, needle insertion, distortion of tissue, and needle angle adjustment [25]. With the application of realtime ultrasound, active needle tracking allows experienced providers to visualize their needle as it travels the tissue layers. Adjustment of needle trajectory, as well as potential confirmatory tip location, can be done with realtime imaging. Furthermore, active scanning allows for readjustment without having to remap when a patient moves from their pre-scanned position. Recent studies testing the feasibility and success of real-time ultrasound for neuraxial block placement have been promising, and the advances in transducer technology have improved the quality of the images acquired. The real-time ultrasound guidance for midline neuraxial blockade is complicated by the acoustic shadows from the vertebrae. The paramedian longitudinal approach provides superior quality images compared to classical ultrasound planes used

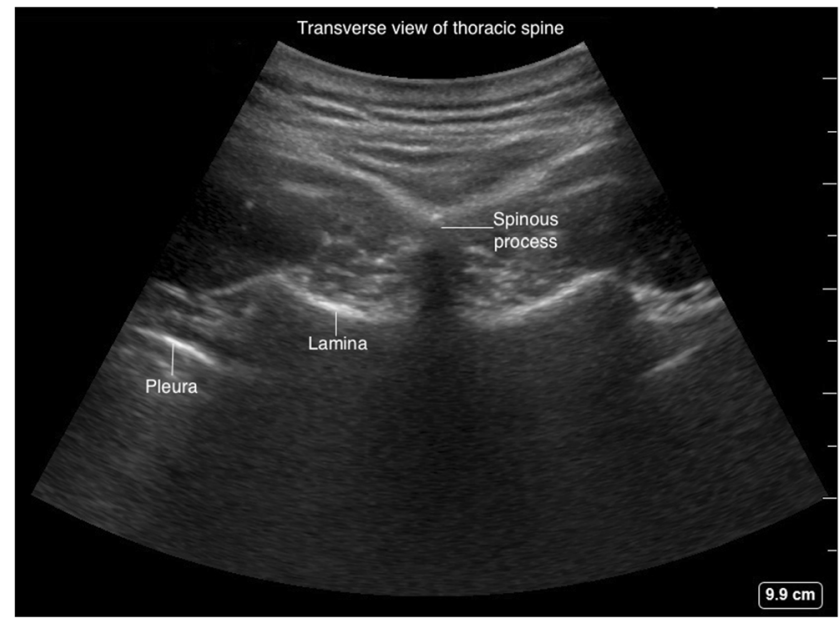

Fig. 24 Transverse view of thoracic spine 
Table 1 Summary of systematic/narrative reviews comparing preprocedural ultrasound to landmark palpation for neuraxial procedures

\begin{tabular}{|c|c|c|c|}
\hline Author, Year & Number of studies & Population & Findings \\
\hline $\begin{array}{r}\text { Sidiropoulou } \\
2021[7 \bullet \bullet]\end{array}$ & 32 RCTs (3439 patients) & $\begin{array}{l}\text { Adult patients undergoing neuraxial } \\
\text { procedures }\end{array}$ & $\begin{array}{l}\text { The ultrasound scanning decreases the overall risk of technical } \\
\text { failure (RR } 0.69 ; 99 \% \mathrm{CI}, 0.43 \text { to } 1.10 ; p=0.04 \text { ) and increases the } \\
1 \text { st-attempt success rate (RR } 1.5 ; 99 \% \mathrm{CI}, 1.22 \text { to } 1.86 ; p< \\
0.0001, \mathrm{NNT}=5 \text { ). No difference in procedural times found. }\end{array}$ \\
\hline $\begin{array}{l}\text { Onwochei } \\
2021[8]\end{array}$ & 18 RCTs (1800 patients) & $\begin{array}{l}\text { Non-obstetric adult patients, having } \\
\text { diagnostic and/or therapeutic } \\
\text { neuraxial procedures. }\end{array}$ & $\begin{array}{l}\text { No difference in } 1 \text { st pass success rate (RR } 1.46 ; 95 \% \mathrm{CI}, 0.99 \text { to } \\
2.16 ; p=0.06 \text { ), but effect size favored the ultrasound imaging } \\
\text { group. Preprocedural scanning increased procedural time by } ~ \\
2 \text { min (mean difference } 110.8 \mathrm{~s} ; 95 \% \mathrm{CI}, 31.0 \text { to } 190.7 ; p=0.006 \text { ) } \\
\text { Ultrasound imaging increased the } 1 \text { st skin puncture success rate } \\
\text { (risk ratio } 1.36 ; 95 \% \mathrm{CI}, 1.18 \text { to } 1.57 ; p<0.001 \text { ), and decreased } \\
\text { the need for } \geq 3 \text { skin punctures (risk ratio } 0.46 ; 95 \% \mathrm{CI}, 0.33 \text { to } \\
0.64 ; p<0.001 \text { ). It also reduced the number of needle redirections } \\
\text { (mean difference }-1.24 ; 95 \% \mathrm{CI},-2.32 \text { to }-0.17 ; p=0.020 \text { ) and } \\
\text { the incidence of bloody tap (risk ratio } 0.61 ; 95 \% \mathrm{CI}, 0.40 \text { to } 0.93 \text {; } \\
p=0.020 \text { ) }\end{array}$ \\
\hline
\end{tabular}

Shu 2021 [9] 28 RCTs (2813 patients) Adult patients undergoing lumbar punctures

Young 2021 $[10 \bullet \cdot]$

Yoo 2020

Jiang 2020

Gottlieb 201912 RCTs (957 patients) [13]

Olowoyeye Four studies (308 2019 [14] participants)

Guay 2019

[15]
Narrative review

18 RCTs (1844 patients) Obstetrical patients having neuraxial procedures

Adult patients undergoing lumbar puncture

Neonates and infants for lumbar puncture a neuraxial or peripheral block

The ultrasound imaging reduces the risk of failed procedures $(\mathrm{RR}=$ $0.58,95 \%$ CI 0.39 to $0.85, p=0.005)$ and decreases 1 st attempt failure $(\mathrm{RR}=0.43,95 \% \mathrm{CI} 0.30$ to $0.62, p<0.001)$, mean attempts to success (SMD $=-0.61,95 \% \mathrm{CI}-0.80$ to $-0.43, p<$ $0.001)$ and incidence of complications such as headache and backache ( $\mathrm{RR}=0.63,95 \% \mathrm{CI} 0.46$ to $0.85, p=0.003)$.

Preprocedural ultrasound imaging increases the 1st-pass success rate $(\mathrm{RR}=1.46,95 \% \mathrm{CI}=1.16-1.82, p=0.001)$ with no difference in total procedural time. Sub-group analysis showed an increased benefit of preprocedural ultrasound in patients with predicted difficulty. Ultrasound use decreased postpartum back pain and headache.

Preprocedural ultrasound identified the accurate intervertebral level for a puncture, optimal needle insertion point, and depth of needle advancement for success. Ultrasound imaging also facilitates lumbar neuraxial block for difficult cases, such as obese patients and patients with anatomical abnormalities of the lumbar spine.

Preprocedural ultrasound imaging increased the 1st-pass success rate in patients with predicted difficulty but not in normal patients. Preprocedural ultrasound reduced the number of redirections and punctures and decreased the incidence of vascular puncture and backache. There was no reduction in the overall failure rate. Preprocedural ultrasound prolonged the identification time but not the procedure time.

The success of ultrasound-assisted lumbar puncture was $90 \%$ vs. $81 \%$ for landmark-based technique. The risk difference was $8.9 \%$ $(95 \% \mathrm{CI}=1.2 \%$ to $16.7 \%$ ) with an odds ratio (OR) of $2.22(95 \%$ $\mathrm{CI}=1.03$ to 4.77 ) in favor of the ultrasound group. There were fewer traumatic lumbar punctures in the ultrasound-assisted group $(10.7 \%$ vs. $26.5 \%$; $\mathrm{RD}=-16.4 \%, 95 \% \mathrm{CI}=-27.6 \%$ to $5.2 \% ; \mathrm{OR}=0.28,95 \% \mathrm{CI}=0.18$ to 0.45 ). Ultrasound-assisted lumbar puncture was associated with a shorter time to successful lumbar puncture (6.87 minutes vs. $7.97 \mathrm{~min}$ ), fewer mean needle passes ( 2.07 vs. 2.66$)$, and lower patient pain scores (3.75 vs. 6.31).

No statistically significant difference was found between the ultrasound imaging and landmark groups $(\mathrm{RR}=0.58 ; 95 \% \mathrm{CI}=$ 0.15 to $2.28 ; p=0.44)$. However, ultrasound imaging significantly reduced the risk of a traumatic tap (RR $0.33 ; 95 \% \mathrm{CI}$ 0.13 to $0.82 ; p=0.02$ ).

Pediatric ( $\leq 18$ years of age) patients for Ultrasound guidance reduces the risk of a failed block (risk

difference $-0.16 ; 95 \% \mathrm{CI}-0.25$ to -0.07 ). There was little or no difference in the time taken to perform the block (SMD -0.46 , $95 \% \mathrm{CI}-1.06$ to 0.13 ). Unclear if the number of needle passes is 
Table 1 (continued)

\begin{tabular}{|c|c|c|c|}
\hline Author, Year & Number of studies & Population & Findings \\
\hline & & & $\begin{array}{l}\text { reduced with the use of ultrasound guidance in the pediatric } \\
\text { population (SMD }-0.63,95 \% \mathrm{CI}-1.08 \text { to }-0.18 \text { ). }\end{array}$ \\
\hline $\begin{array}{l}\text { Elgueta } 2016 \\
{[16]}\end{array}$ & Narrative review & $\begin{array}{l}\text { Adult, pediatric, and chronic pain } \\
\text { patients }\end{array}$ & $\begin{array}{l}\text { Compared to conventional palpation of landmarks, preprocedural } \\
\text { scanning results in fewer needle passes/insertions and skin } \\
\text { punctures for neuraxial blocks in obstetrical and surgical patients. } \\
\text { The benefits seem most noticeable when expert operators carry } \\
\text { out the ultrasound examination and for patients with predicted } \\
\text { difficult spinal anatomy. }\end{array}$ \\
\hline $\begin{array}{l}\text { Lam } 2016 \\
\quad[17]\end{array}$ & $\begin{array}{l}13 \text { studies }(4 \mathrm{RCTs}, 6 \\
\text { observational \& one } \\
\text { case series }\end{array}$ & $\begin{array}{l}\text { Pediatric patients with mixed surgical } \\
\text { population }\end{array}$ & $\begin{array}{l}\text { Ultrasound guidance improves needling time, predicts epidural } \\
\text { depth, allows visualization of the catheter and local anesthetic } \\
\text { spread, and improves block quality. }\end{array}$ \\
\hline $\begin{array}{l}\text { Perlas } 2016 \\
\quad[18 \bullet \bullet]\end{array}$ & $\begin{array}{l}31 \text { studies and one } \\
\text { meta-analysis }\end{array}$ & $\begin{array}{l}\text { Adult patients for lumbar spinal and } \\
\text { epidural anesthesia }\end{array}$ & $\begin{array}{l}\text { Neuraxial ultrasound identifies the lumbar intervertebral space more } \\
\text { accurately than landmark technique and results in increased } \\
\text { success and ease of performance. } \\
\text { Ultrasound imaging appears to reduce the risk of traumatic } \\
\text { procedures. }\end{array}$ \\
\hline $\begin{array}{l}\text { Shaikh } 2013 \\
\text { [19] }\end{array}$ & $\begin{array}{l}14 \text { studies }(1334 \\
\text { patients) }\end{array}$ & $\begin{array}{l}\text { Adult patients undergoing lumbar } \\
\text { punctures and epidural } \\
\text { catheterizations }\end{array}$ & $\begin{array}{l}\text { Ultrasound imaging reduces the risk of failed procedures (RR } 0.21 \text {; } \\
95 \% \text { CI } 0.10 \text { to } 0.43 ; p<0.001 \text { ). Risk reduction is similar for } \\
\text { lumbar punctures (RR } 0.19 ; 0.07 \text { to } 0.56 ; p=0.002 \text { ) or epidural } \\
\text { catheterizations (RR } 0.23 ; 0.09 \text { to } 0.60 ; p=0.003 \text { ). Ultrasound } \\
\text { imaging reduces the risk of traumatic procedures (RR } 0.27 ; 0.11 \\
\text { to } 0.67 ; p=0.005 \text { ), number of insertion attempts (mean difference } \\
-0.44 ; 0.64 \text { to }-0.24 ; p<0.001 \text { ), and number of needle } \\
\text { redirections (mean difference }-1.00 ;-1.24 \text { to }-0.75 ; p<0.001 \text { ). }\end{array}$ \\
\hline $\begin{array}{l}\text { Schnabel } \\
\quad 2012[20]\end{array}$ & $6 \mathrm{RCT}$ (659 patients) & Obstetric population & $\begin{array}{l}\text { Ultrasound-facilitated neuraxial blocks required a lower number of } \\
\text { puncture attempts (MD: }-0.92 ; 95 \% \text { CI: }-1.11 \text { to }-0.74 ; p< \\
0.00001 \text { ). The first attempt success rate with ultrasound guidance } \\
\text { in predicted difficult patients was } 71 \% \text { in comparison to } 20 \% \\
\text { using a conventional technique. Patients receiving } \\
\text { ultrasound-assisted neuraxial blocks had a lower rate of } \\
\text { procedure-related complications (post-dural puncture headache or } \\
\text { vascular puncture). }\end{array}$ \\
\hline
\end{tabular}

$R R$ risk ratio, $C I$ confidence interval, $M D$ mean difference, $S M D$ standardized mean difference, $R C T$ randomized controlled trial

for preprocedural "mapping." Due to the possibility of neurotoxicity of ultrasound gel, saline is commonly used as a coupling medium for real-time imaging, reducing image quality [26]. Currently, real-time ultrasound scanning is a cumbersome and challenging technique with limited clinical utility.

\section{Advances}

Technological improvements in ultrasound imaging have been dramatic over the last 20 years, and includes experiments with three-dimensional (3D) and four-dimensional (4D) imaging [27]. A real-time 3D ultrasound imaging in conjunction with innovative needle-guide for midline epidural needle insertion technique has been described in animal models [28]. Further, the feasibility of using 4D ultrasound on cadavers for real-time epidural placement found that $4 \mathrm{D}$ ultrasound has the potential to improve operator orientation of the neuraxis but at the expense of decreased resolution, frame rate, and needle visibility
[29]. The incorporation of a new signal processing technology to enhance bone imaging and including 3D navigation has led to production of newer devices to locate the ideal puncture site [30]. Artificial intelligence integration into ultrasound machines was recently reported $[31 \cdot 32]$. Machine learning and advances in ultrasound technology have already proved to be successful in the field of cardiac imaging [33]. We can therefore expect to see something similar that would prove to be superior to current technology and increase the image quality and ease of performing real-time ultrasound-guided neuraxial anesthesia in future.

\section{Conclusion}

Neuraxial ultrasound imaging should be in the skill set of every anesthesiologist who routinely performs lumbar or thoracic neuraxial blockade. Evidence for the clinical benefits of ultrasound "mapping" prior to performing neuraxial 
blocks is mounting. Preprocedural imaging of the neuraxis minimizes the technical difficulty of spinal and epidural placement. It helps to accurately identify the midline, vertebral level, intervertebral space, and predicts the depth to epidural and intrathecal spaces. Ultrasound imaging also provides information about the best angle and approach for a successful block. Compared to landmark techniques, ultrasound use results in fewer needle passes and skin punctures in both obstetric and non-obstetric surgical patients. Studies consistently show that the use of ultrasound increases the success rate and ease of neuraxial block performance. These benefits are most evident when experienced operators perform the ultrasound examination and for patients with predicted difficult spinal anatomy. Evidence suggests that ultrasound usage for neuraxial procedures reduces the risk of traumatic procedures and, thus, may increase safety. The ultrasound equipment with curvilinear probes are readily available, especially in obstetric units, as they are used for fetal scanning and monitoring. Neuraxial ultrasound scanning is a non-invasive procedure with the only possible downside that it may increase the procedure-related time by approximately $2 \mathrm{~min}$. However, the evidence related to increased procedural time is conflicting and may depend on the clinical situation. We recommend using preprocedural neuraxial ultrasound imaging routinely to acquire and maintain this unique skillset. This will aid clinicians to deal with challenging neuraxial procedures when required.

Acknowledgements We thank Darlene Chapman (Manager, Library Services) from IWK Health Centre (Halifax), Leah Boulos (Evidence Synthesis Coordinator, Maritime SPOR SUPPORT Unit-Research Services, Halifax) for helping us with the literature search, Amanda Mendelsohn from Cleveland Clinic Center for Medical Art and Photography for medical illustrations, and Dr. Steven Porter for comments on the manuscript.

\section{Declarations}

Conflict of Interest The authors do not have any potential conflicts of interest to disclose.

Human and Animal Rights and Informed Consent This article does not contain any studies with human or animal subjects performed by any of the authors.

Open Access This article is licensed under a Creative Commons Attribution 4.0 International License, which permits use, sharing, adaptation, distribution and reproduction in any medium or format, as long as you give appropriate credit to the original author(s) and the source, provide a link to the Creative Commons licence, and indicate if changes were made. The images or other third party material in this article are included in the article's Creative Commons licence, unless indicated otherwise in a credit line to the material. If material is not included in the article's Creative Commons licence and your intended use is not permitted by statutory regulation or exceeds the permitted use, you will need to obtain permission directly from the copyright holder. To view a copy of this licence, visit http://creativecommons.org/licenses/by/4.0/.

\section{References}

Papers of particular interest, published recently, have been highlighted as:

- Of importance

•- Of major importance

1. Chin KJ. Recent developments in ultrasound imaging for neuraxial blockade. Curr Opin Anaesthesiol. 2018;31:608-13.

2. Ghosh S, Madjdpour C, Chin K. Ultrasound-guided lumbar central neuraxial block. Bja Educ. 2016;16:213-20.

3. Whitty R, Moore M, Macarthur A. Identification of the lumbar interspinous spaces: palpation versus ultrasound. Anesth Analg. 2008;106:538-40.

4. Chin KJ, Karmakar MK, Peng P. Ultrasonography of the adult thoracic and lumbar spine for central neuraxial blockade. Anesthesiology. 2011;114:1459-85 This review article describes the sono-anatomy, technical description of ultasound imaging of spine and evidence review.

5. Karmakar MK, Li X, Ho AM, Kwok WH, Chui PT. Real-time ultrasound-guided paramedian epidural access: evaluation of a novel in-plane technique. Br J Anaesth. 2009;102:845-54.

6. Hughes RJ, Saifuddin A. Imaging of lumbosacral transitional vertebrae. Clin Radiol. 2004;59:984-91.

7.• Sidiropoulou T, Christodoulaki K, Siristatidis C. Pre-Procedural Lumbar Neuraxial Ultrasound-A Systematic Review of Randomized Controlled Trials and Meta-Analysis. Healthcare. 2021:9 A meta-analysis retrieving 32 trials comparing preprocedural lumbar ultrasounds to palpations for neuraxial procedures in various clinical settings showing significant benefit in terms of technical failure and first attempt-success rate with ultrasound.

8. Onwochei D, Nair G, Young B. Desai N Conventional landmark palpation versus preprocedural ultrasound for neuraxial procedures in nonobstetric patients: A systematic review with meta-analysis and trial sequential analysis of randomised controlled trials. Eur J Anaesthesiol. 2021.

9. Shu L, Huang J, Liu JC. Efficacy of ultrasound guidance for lumbar punctures: a systematic review and meta-analysis of randomised controlled trials. Postgrad Med J. 2021;97:40-7.

10.• Young B, Onwochei D, Desai N. Conventional landmark palpation vs. preprocedural ultrasound for neuraxial analgesia and anaesthesia in obstetrics - a systematic review and meta-analysis with trial sequential analyses. Anaesthesia. 2021;76:818-31 A metaanalysis performed in obstetric patients including 22 trials showed preprocedural ultrasound increaed the first-pass success rate and decreased complications like postpartum back pain and headache. The authors stated that preprocedural ultrasound should be considered as standard of care in obstetrics.

11. Yoo S, Kim Y, Park SK, Ji SH, Kim JT. Ultrasonography for lumbar neuraxial block. Anesth Pain Med. 2020;15:397-408.

12. Jiang L, Zhang F, Wei N, Lv J, Chen W, Dai Z. Could preprocedural ultrasound increase the first-pass success rate of neuraxial anesthesia in obstetrics? A systematic review and metaanalysis of randomized controlled trials. J Anesth. 2020;34:43444.

13. Gottlieb M, Holladay D, Peksa GD. Ultrasound-assisted Lumbar Punctures: A Systematic Review and Meta-Analysis. Acad Emerg Med. 2019;26:85-96.

14. Olowoyeye A, Fadahunsi O, Okudo J, Opaneye O, Okwundu C. Ultrasound imaging versus palpation method for diagnostic lumbar 
puncture in neonates and infants: a systematic review and metaanalysis. BMJ Paediat Open. 2019;3:e000412-2018.

15. Guay J, Suresh S. Kopp S The use of ultrasound guidance for perioperative neuraxial and peripheral nerve blocks in children. Cochrane Database Syst Rev. 2019;2:CD011436.

16. Elgueta MF, Duong S, Finlayson RJ, Tran DQ. Ultrasonography for neuraxial blocks: a review of the evidence. Minerva Anestesiol. 2017;83:512-23.

17. Lam DK, Corry GN, Tsui BC. Evidence for the use of ultrasound imaging in pediatric regional anesthesia: a systematic review. Reg Anesth Pain Med. 2016;41:229-41.

18.•Perlas A, Chaparro LE, Chin KJ. Lumbar Neuraxial Ultrasound for Spinal and Epidural Anesthesia: A Systematic Review and MetaAnalysis. Reg Anesth Pain Med. 2016;41:251-60 This systematic review including 31 clinical trials examined the evidence for preprocedural neuraxial ultrasound which showed benefit in accurate identification of intervertebral space and reduced risk of traumatic procedures.

19. Shaikh F, Brzezinski J, Alexander S, Arzola C, Carvalho JCA, Beyene J, et al. Ultrasound imaging for lumbar punctures and epidural catheterisations: systematic review and meta-analysis. BMJ. 2013;346:f1720.

20. Schnabel A, Schuster F, Ermert T, Eberhart LH, Metterlein T, Kranke P. Ultrasound guidance for neuraxial analgesia and anesthesia in obstetrics: a quantitative systematic review. Ultraschall Med. 2012;33:E132-E7.

21. Li M, Ni X, Xu Z, Shen F, Song Y, Li Q, et al. Ultrasound-assisted technology versus the conventional landmark location method in spinal anesthesia for cesarean delivery in obese parturients: a randomized controlled trial. Anesth Analg. 2019;129:155-61.

22. Park SK, Bae J, Yoo S, Kim WH, Lim YJ, Bahk JH, et al. Ultrasound-assisted versus landmark-guided spinal anesthesia in patients with abnormal spinal anatomy: a randomized controlled trial. Anesth Analg. 2020;130:787-95.

23. Auyong DB, Hostetter L, Yuan SC, Slee AE, Hanson NA. Evaluation of Ultrasound-Assisted Thoracic Epidural Placement in Patients Undergoing Upper Abdominal and Thoracic Surgery: A Randomized, Double-Blind Study. Reg Anesth Pain Med. 2017;42:204-9 A randomized, double blind study evaluating the effect of preprocedural ultrasound of thoracic spine for epidural catheterization which did not significantly reduced the time required to identify the thoracic epidural space, but showed decreased number of needle skin punctures and less mean pain scores in ultrasound group compared to palpation group.

24. Hasanin AM, Mokhtar AM, Amin SM, Sayed AA. Preprocedural ultrasound examination versus manual palpation for thoracic epidural catheter insertion. Saudi J Anaesth. 2017;11:62-6.

25. Grau T, Leipold RW, Conradi R, Martin E. Ultrasound control for presumed difficult epidural puncture. Acta Anaesthesiol Scand. 2001;45:766-71.

26. Pintaric TS, Hadzic A, Strbenc M, Podpecan O, Podbregar M, Cvetko E. Inflammatory response after injection of aqueous gel into subarachnoid space in piglets. Reg Anesth Pain Med. 2013;38:100-5.

27. Beigi P, Malenfant $P$, Rasoulian A, Rohling R, Dube A, Gunka V. Three-dimensional ultrasound-guided real-time midline epidural needle placement with epiguide: a prospective feasibility study. Ultrasound Med Biol. 2017;43:375-9.

28. Stone J, Beigi P, Rohling R, Lessoway V, Dube A, Gunka V. Novel 3D ultrasound system for midline single-operator epidurals: a feasibility study on a porcine model. Int J Obstet Anesth. 2017;31:51-6.

29. Belavy D, Ruitenberg MJ, Brijball RB. Feasibility study of realtime three-/four-dimensional ultrasound for epidural catheter insertion. Br J Anaesth. 2011;107:438-45.

30. Singla P, Dixon AJ, Sheeran JL, Scalzo D, Mauldin FW Jr, Tiouririne M. Feasibility of spinal anesthesia placement using automated interpretation of lumbar ultrasound images: a prospective randomized controlled trial. J Anesth Clin Res. 2019;10.

31. Ghisi D, Tomasi M, Giannone S, et al. A randomized comparison between Accuro and palpation-guided spinal anesthesia for obese patients undergoing orthopedic surgery. Reg Anesth Pain Med. 2019; A randomized controlled study comparing hand-held ultrasound device with conventional palpation for spinal anesthesia in obese patients undergoing orthopedic surgery showed reduced number of needle redirections and passes with use of hand-held ultrasound.

32. Pesteie M, Lessoway V, Abolmaesumi P, Rohling RN. Automatic localization of the needle target for ultrasound-guided epidural injections. Trans Med Imaging. 2018;37:81-92.

33. Ghorbani A, Ouyang D, Abid A, He B, Chen JH, Harrington RA, et al. Deep learning interpretation of echocardiograms. NPJ Digit Med. 2020;3:10.

Publisher's Note Springer Nature remains neutral with regard to jurisdictional claims in published maps and institutional affiliations. 